\title{
Intromisiones profesionales y juicios estéticos en la arquitectura de la Granada finisecular: Arzobispado, Academia y Universidad
}

\section{Professional intromission and Aesthetic Judgement in Late Nineteenth-Century Architecture in Granada: Archbishopric, Academy and University}

\author{
DAVID Martín LÓPEZ*
}

\begin{abstract}
RESUMEN
ABSTRACT

El siglo XIX fue propicio para la In the Nineteenth century, Granada was an appropriate place for the consolidation of the new architecture. The aim of this paper is to present one of the most relevant mason architects of this period: Juan Monserrat through his importance in the institutional problems which happened in Granada between the Archbishopric, the University and the Fine Arts' Academy of San Fernando. The professional intrusion of mason masters in architectural works and the aesthetical resolutions of the Academy are some aspects analysed in the following text.
\end{abstract}

\footnotetext{
* Departamento de Historia del Arte. Universidad de Granada.
} 


\begin{abstract}
PALABRAS CLAVE
Arquitectura contemporánea, Arquitectos, Maestros de obra, Academia de Bellas Artes de San Fernando, Universidad, Cabildo Catedral, Arzobispado, Masonería, Estética masónica, Proyectos de edificación.
\end{abstract}

IDENTIFICADORES

Monserrat y Vergés, Juan; GiménezArévalo, Francisco; Díaz de Lozada, Cecilio; Montells y Nadal, Francisco; Abásolo, José Ladislao; Pugnaire, Juan; Baglietto, Santiago.

TOPÓNIMOS

Granada, Madrid, Almería.

PERÍODO

Siglos $x I x y x x$.

\section{KEYWORDS}

Contemporary architecture, Architects, Mason masters, Fine Arts' Academy of San Fernando, University, Cathedral, Archibishopric, Masonry, Masonic aesthetic, Construction projects.

\section{IDENTIFIERS}

Monserrat y Vergés, Juan; GiménezArévalo, Francisco; Díaz de Lozada, Cecilio; Montells y Nadal, Francisco; Abásolo, José Ladislao; Pugnaire, Juan; Baglietto, Santiago.

PLACE NAMES

Granada, Madrid, Almería.

\section{PERIOD}

19th and 20th centuries.

Este texto pretende ser una aproximación, con nueva documentación aportada, a las complejas y difíciles relaciones institucionales Academia-Iglesia, y AcademiaUniversidad que se producen en Granada en el último tercio del siglo XIX. El debate estético patrimonial sobre las reformas del Colegio de San Pablo, sede de la Universidad Literaria de Granada y de su órgano rector, así como la intrusión profesional de los maestros de obra en la Catedral granadina tuvieron una resonancia inusitada dentro de la Real Academia de Bellas Artes de San Fernando. Se abordarán, por tanto, dos aspectos de la historia arquitectónica y patrimonial de Andalucía que quedan interrelacionados a través de su principal protagonista: Juan Monserrat y Vergés, arquitecto masón de origen catalán que detentaría los cargos institucionales de Arquitecto Director del Arzobispado granadino y de su Universidad. Estos cargos, para los que fue nombrado desde Madrid en 1877, no estuvieron exentos de una polémica extrema. 


\section{GRANADA, LA CIUDAD EMERGENTE}

La ciudad de Granada, a finales del siglo XIX, experimenta un proceso transformador y regenerador en muchos de sus ámbitos, dejando atrás su decadencia del inicio de la centuria. A Granada «[...] languidecente y ensimismada, pálido reflejo de lo que había sido, le quedará, sólo, esa aureola de ciudad encantada que exaltó la fantasía de los románticos del siglo que se refugiaron en ella, física o imaginariamente, y ensalzaron y difundieron su fama y su imagen utilizando como vehículos la pintura, la poesía, la literatura o la música»".

Pero sin embargo, en torno a 1870, esta provincia andaluza se recuperaba a grandes pasos, contando con siete fundiciones de plomo y tres de hierro. Los negocios e industrias del azúcar se habían iniciado ya en 1868. En ellos, participa una nueva burguesía de industriales e inversores como Juan Ramón la Chica, y los banqueros José María Rodríguez y José González Aurioles². En buena medida, este cambio económico que se produce desde mediados del siglo XIX, estuvo propiciado por las nuevas explotaciones agrícolas, el auge de la caña de azúcar o la industrialización de La Vega y la costa granadina, provocando un despertar absoluto del letargo económico sufrido en el siglo anterior. La ciudad se convertía así, en una urbe más de España, que se adentraba tímidamente en el desarrollo lógico de toda capital de provincia finisecular.

La arquitectura contribuyó, con las nuevas tendencias estilísticas, a crear precisamente esa nueva imagen de la capital granadina como ciudad emergente. Muestra de esta situación es la formulación utópica de la Gran Vía de Colón, que atraviesa y disecciona el centro histórico de Granada. Tras un acontecimiento, a priori, exclusivamente económico, las familias de industriales como las de Francisco Giménez-Arévalo o López Rubio generan, como promotores, una serie de reformas y ampliaciones urbanísticas en el casco antiguo de la ciudad. Estas actuaciones aparte de otras racionalizaciones del espacio, subrayarían el concepto de una ciudad nueva, abierta al ocio y al esparcimiento, a la modernidad, al tranvía y al boulevard, creando mansiones periféricas y pequeños hoteles céntricos como la residencia del banquero Aurioles o el Palacio de Los Patos de la familia Agrela.

Ángel Ganivet tachaba estas actuaciones de locura diabólica: «[...] a Granada ha llegado la epidemia del ensanche y como no había razón para que nos ensancháramos porque teníamos nuestros ensanches naturales... y más nos sobraba po-

1 CAPARRÓS MASEGOSA, L: «Artes plásticas en la prensa granadina del siglo XIX», Biblioteca de Arte y Arqueología. Granada, Universidad de Granada, 2001, p. 19.

2 GAY ARMENTEROS, J. y VIÑES MILLET, C.: Historia de Granada. IV. La época contemporánea. Granada, Editorial Quijote, 1982, pp. 27-28. 


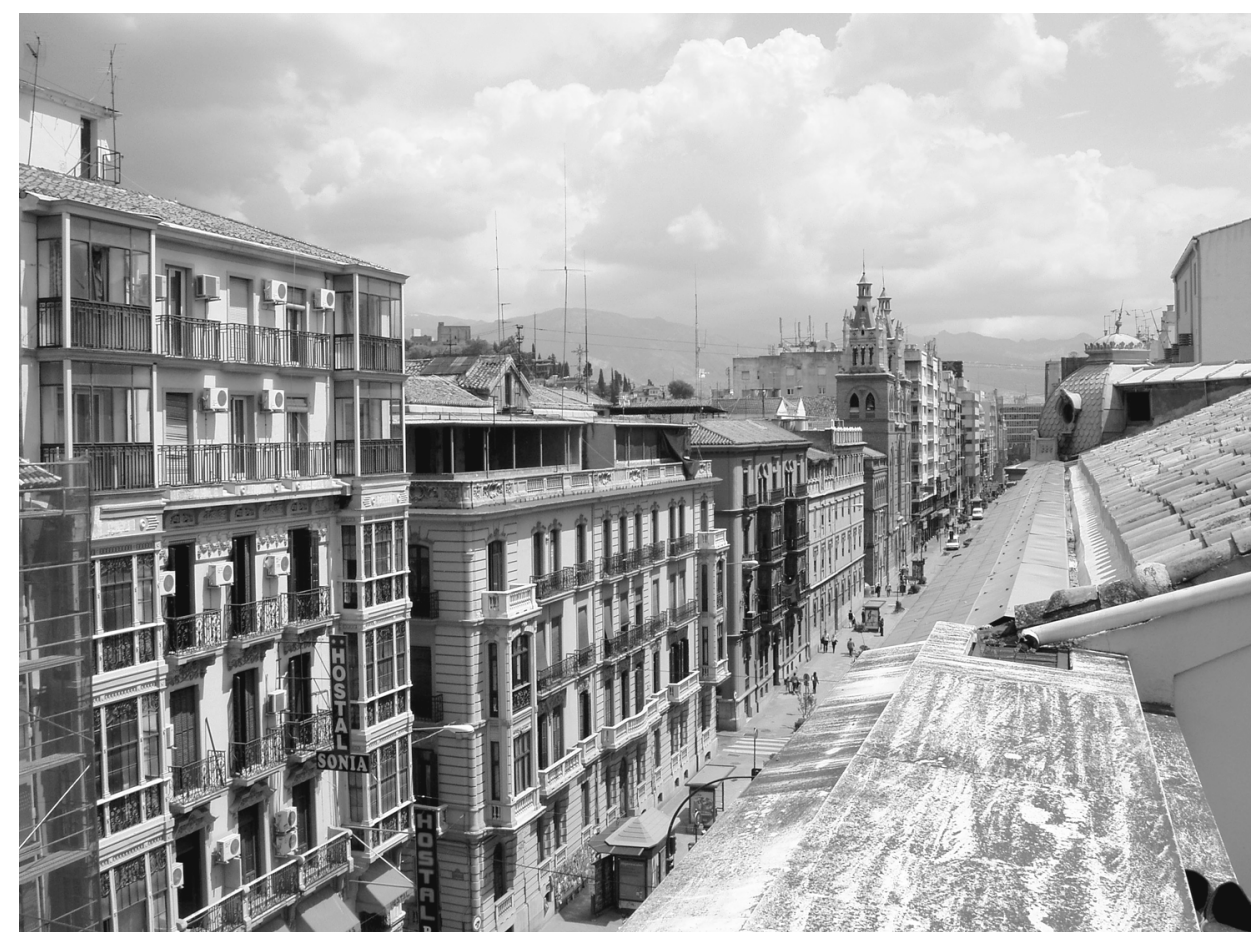

Fig. 1. Aspecto parcial de la Gran Vía de Colón, Granada.

blación, concebimos la idea famosa de ensancharnos por el centro y el proyecto diabólico de destruir la ciudad»3.

\section{LA UNIVERSIDAD, ESTÉTICA PATRIMONIAL DE LA LAICIDAD}

En este ambiente de cambios culturales y políticos, más que estéticos y urbanísticos, se reformaría también la llamada Universidad Literaria de Granada, cuyo edificio principal se encontraba, desde tiempos de Carlos III, en el Colegio de San Pablo -histórico Colegio de los Jesuitas en la Plaza de la Universidad o de Las Escuelas-. En 1871, el Rector Montells y Nadal, inicia junto al Arquitecto-Director de las obras, Santiago Baglietto, una de las polémicas más importantes entre la Universidad, la Academia y la Comisión Provincial de Monumentos, cuestión

3 Cita de Ángel Ganivet recogida en el «Estudio introductorio» de J. Bosque Maurel en la edición facsímil del Diccionario Geográfico-estadístico-Histórico de España y sus posesiones de ultramar de F. Madoz -Granada, 1987-, extraído de CAPARRÓS MASEGOSA, L.: Op. Cit., p. 28. 


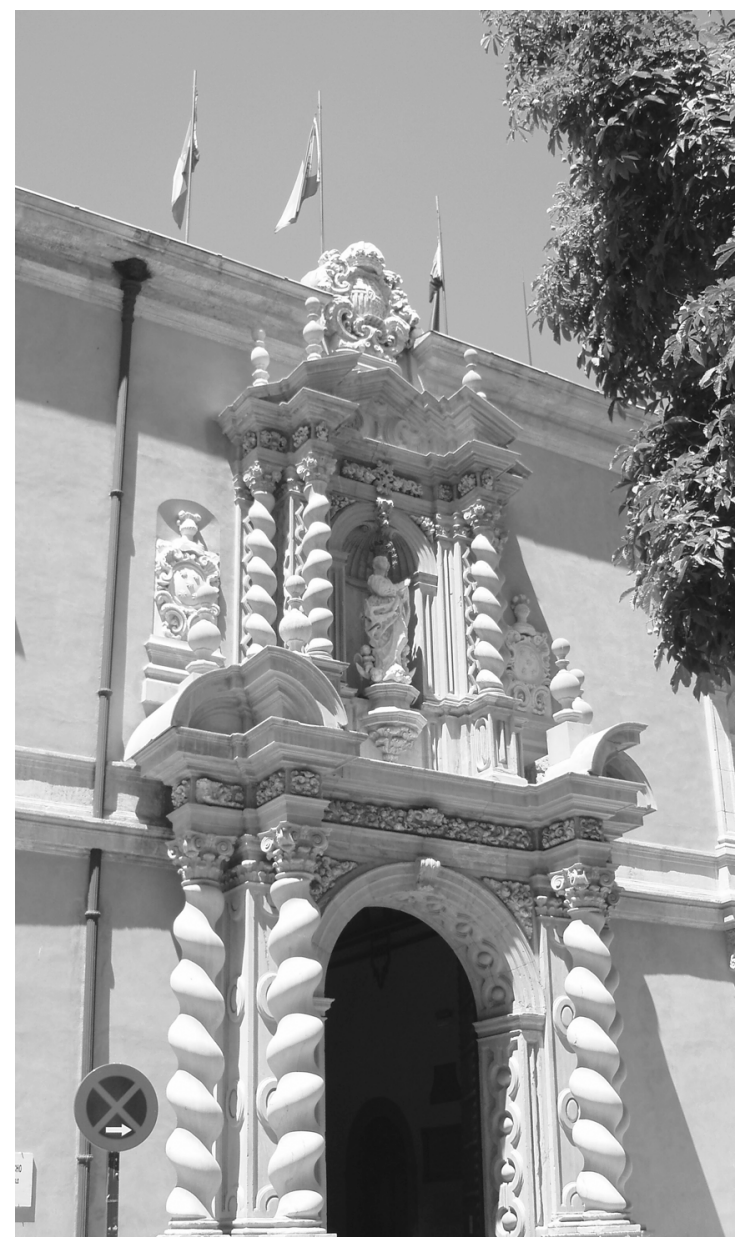

Fig. 2. Portada barroca inmaculista de la Fachada de la Universidad Literaria (antiguo Colegio de San Pablo). Plaza de la Universidad. Granada.

que continuará hasta 1879, fecha de la conclusión de las reformas ya por parte de Juan Monserrat y Vergés.

La Universidad granadina había estado frente a la Catedral hasta tiempos de Carlos III, en el actual Palacio Arzobispal, contiguo al Colegio de la Santa Cruz de la Fe. Es en 1769 cuando la Universidad tiene un nuevo espacio para desarrollar la actividad docente: el Colegio de San Pablo o de los Regulares ${ }^{4}$. Y es que «[...] aun-

4 V.V.A.A.: Universidad y Ciudad. Granada, Universidad de Granada, 1997, p. 77. 
que la reforma de los estudios se habría verificado de todas formas, la extinción de la Compañía de Jesús, pieza esencial para el panorama educativo, obligó a plantearla con caracteres de urgencia. No se trataba sólo de cubrir un vacío, de arbitrar una situación, sino de poner en planta un nuevo sistema educativo, más acorde con la marcha de los tiempos; programa ambicioso que sólo alcanzó éxitos parciales, incluso en la enseñanza universitaria, que era la meta perseguida con mayor interés" ${ }^{5}$.

En el Archivo Histórico de la Universidad de Granada se encuentran numerosas referencias importantes para el urbanismo granadino en torno a la Universidad Literaria, actual Facultad de Derecho. Así, existe una interesante correspondencia de los arquitectos, el Rector, el órgano de gobierno de la Universidad, la Real Academia de Bellas Artes de San Fernando con copias y cartas oficiales de la Administración Pública, tanto de Madrid como del Ayuntamiento de Granada.

Durante el año 1776, y ante las reformas de la enseñanza, se habilitaron más de ocho cátedras que se impartían en las ocho aulas de la antigua sede jesuítica. Pero como estructura física, ésta se había quedado insuficiente a comienzos del siglo xIx. En 1802, y aun sabiendas de la existencia de una acuciante necesidad de espacio para la docencia, los estudiantes del Colegio de Santa Cruz tuvieron que ser integrados en el de Santa Catalina, y el local que ocupaban en la sede jesuítica fue destinado al acuartelamiento de Infantería por parte de la Administración Militar del Estado - hecho por el que se conocería más tarde como Cuartel de la Compañía ${ }^{6}$ - Este complicado desenlace político y burocrático, provocaría una gran incertidumbre entre la clase académica granadina, que sin pretenderlo, al pasar este lugar a manos del poder militar, parecía «[...] que el recinto universitario albergaba una estructura militar en su base ${ }^{7}$. Pero además esta circunstancia hacía que por otro lado los colegiales no residieran en la misma sede universitaria, quedando expuestos, como comentaban en la época, a todos los vicios y a las malas costumbres de la ciudad.

El Rector de la Universidad Francisco Montells y Nadal, en su obra sobre la Historia del origen y fundación de la Universidad de Granada de las que existieron en su distrito, de los Colegios, Cátedras y Escuelas que de ella dependían y cuantas noticias pueden servir para ilustrar esta materia con arreglo a lo mandado en la última circular del Excmo. Sr. Ministro de Fomento, de 6 de Abril de 1869, obra impresa en Granada en 1870, pone de manifiesto aquellas inquietudes cita-

5 DOMínGUEZ ORTIZ, A.: Carlos IIl y la España de la llustración. Madrid, Alianza Editorial, 1988, pp. $161-162$.

6 V.V.A.A.: Op. Cit., p. 101

7 Idem, p. 101. 


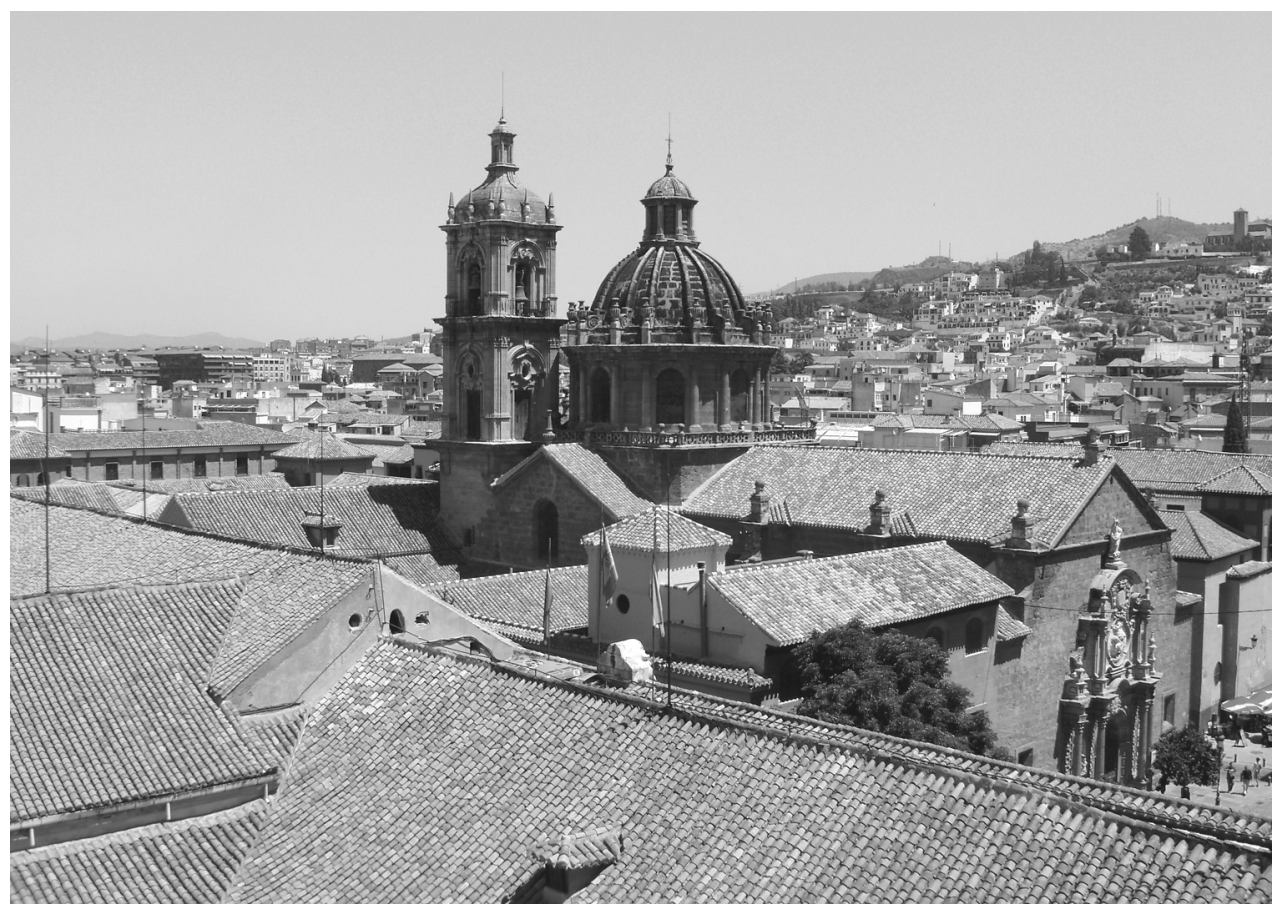

Fig. 3. Iglesia de los Santos Justo y Pastor desde el torreón-observatorio de Monserrat Vergés en la Antigua Universidad Literaria (Facultad de Derecho), Granada.

das y las vicisitudes del año 1808, cuando tuvieron que alojar y acoger en la propia sede universitaria a las tropas del Ejército y a la Junta Suprema ${ }^{8}$.

Es en 1871 cuando comienzan las anheladas obras en la Universidad, con intenciones manifiestas desde 1859, y que tendrían una clara repercusión en el entramado urbanístico del centro histórico granadino. El mismo día de la entrega del Cuartel a la Universidad, comenzaban las obras para su derribo, éste contemplado según el proyecto de ampliación y reforma de la Universidad de Granada de Santiago Baglietto. El citado Rector, Montells y Nadal, los remitió a Madrid para su aprobación por parte de la Real Academia de Bellas Artes de San Fernandoª,

8 Ibidem, pp. 101-102. Cfr. MONTELLS y NADAL, F.: Historia del origen y fundación de la Universidad de Granada de las que existieron en su distrito, de los Colegios, Cátedras y Escuelas que de ella dependían y cuantas noticias pueden servir para ilustrar esta materia con arreglo a lo mandado en la última circular del Excmo. Sr. Ministro de Fomento, de 6 de Abril de 1869. Granada, Imprenta de Indalecio Ventura, 1870 , p. 443.

9 Archivo Histórico de la Universidad de Granada (AHUG) Legajo 1100, pieza 1 sin clasificar (s. c.). y V.V.A.A.: Op. Cit., pp. 111-112. 
como máximo órgano controlador del gusto estético y supervisor de la nueva arquitectura oficial y de las reformas que se hacían en edificios ya existentes. La idoneidad de conservar o no la fachada antigua de la Universidad Literaria generará una cantidad ingente de documentos entre las diversas instituciones responsables, contando, en ocasiones con duplicidad de documentación entre el Archivo Histórico de la Universidad y el Archivo de Alcalá de Henares, y otros archivos como el Histórico Municipal de Granada y el de la Academia de San Fernando.

Técnicamente el hecho de anexar el Cuartel a la Universidad y separarlo así de la Colegiata de los Santos Justo y Pastor, obligaba a abrir una pequeña callejuela entre ambos, dignificando la fachada universitaria que hasta entonces - $\mathrm{y}$ en la actualidad - tenía su entrada en ángulo con la plaza de la Universidad. Se creaba, por tanto, un espacio nuevo en el entramado urbanístico de la ciudad. El trazado de la nueva calle, llamada de Riaño, iba a conectar transversalmente con una existente: la calle de la Compañía — hoy en día también cerrada, mediante dos portalones y arcadas-.

No obstante la polémica en las reformas no surgió en la demolición del Cuartel o en la ejecución planimétrica de las nuevas vías urbanas, sino por la incertidumbre y el devenir patrimonial de la fachada inmaculista del Colegio jesuítico. En el primer proyecto, Santiago Baglietto respetaba la fachada barroca pero la intención era trasladar la portada al centro del recinto apreciable desde la plaza, para estar así en eje de simetría con el espacio creado. Sin embargo, en su diseño de 1875, el arquitecto apostaba por una estructura más nítida, con un corte clasicista-romántico, imponiendo una fachada deudora del neoclasicismo institucional aunque ecléctica a la vez, sin cabida para adaptar la primigenia portada marmórea.

Cuando la calle Riaño estuviera abierta, la nueva portada planteada quedaría en el primer tercio del total de la fachada que da a la plaza, teniendo como lugar de referencia la calle de las Escuelas - hoy calle Escuelas-, en eje con la plaza de la Universidad - denominación actual—. Se abrirían vanos en su planta baja, algo que no existía ni siquiera en el diseño de la fachada de 1871.

Todo esto llevó sin pretenderlo a una complejidad de trámites burocráticos, dictámenes oficiales y quejas públicas que no habían tenido precedentes en la provincia. El primer arquitecto de las obras conjuntamente con el Rector de la Universidad, Francisco Montells y Nadal, suscitarían uno de los debates estéticos más importantes en la Granada del siglo xIx. En la memoria adjunta al proyecto de Reforma, Santiago Baglietto se mostraba partidario de quitar la portada barroca con la Inmaculada, realizada en la época de los jesuitas, para proponer una nueva fachada con alegorías de la ciencias, con Isaac Newton o Raimundo Lull, y de las letras con Alfonso X El Sabio, rematando el tímpano de la portada el omnipresente emperador Carlos V. Se intentaba laicizar de esta manera todo el espacio univer- 
sitario, obviando la relación jesuítica anterior, circunstancia que pesaba en las memorias constructivas previas.

En esa idea, Baglietto afirmaba que «[...] siendo el todo del local una fundación del P.P. Jesuitas como dicho es, no debe cuasar extrañeza que la puerta del actual Universidad, en el diseño $N^{\circ}$ 4. con una suntuosa decoracion prescindiendo de su buen o mal gusto, tuviese el caracter de entrada à una Iglesia; y tanto es así que en el segundo cuerpo de la misma se halla una estatua de marmol blanco que representa, N. S. de la Concepcion. Una portada de este genero se abiene muy mal con el destino que hoy tiene lo que antes fue colegio de Jesuitas, tanto mas cuanto que hallandose situada en el dia en un angulo entrante de la fachada, toda vez que esta se prolonga en la estension de setenta y nueve metros en la totalidad con la nueva calle [...] Declarada y justificada ya la necesidad de desmontar la actual portada hubiera sido altamente reprensible si esta misma se hubiera colocado en el centro de la nueva fachada aun cuando se hubiera podido abenir bien en sus diversas alturas los cuerpos de que consta, mas la ornacina de la Virgen por lo que se comprenderá fácilmente que no podria avenirse bien con un balcon y no hubiera podido ponerse sin solamente la Virgen condenando aquel, en cuyo caso se quitaban las luces del Rectoral y resultaría siempre la entrada de un templo. Por ello debe tenerse presente que siendo el aspecto esterior de los edificios aunque materia inerte lo que a primera vista llama la atención del observador manifestarlo palpablemente lo que son sin necesidad de preguntarlo, hubiera sido ridiculo por demas que se pusiera una portada de Iglesia en un edificio profano aun cuando se diga que este lugar es el santuario de las ciencias y las letras: por muy sagrado que se quiera considerar este edificio, no deja siempre de ser profano» ${ }^{10}$.

Como si de un ejemplo previo a las reflexiones sobre la arquitectura parlante de Aldo Rossi, Rector y Arquitecto-director manifestaban que la institución universitaria en España era laica, y la Universidad Literaria debía ser un edificio netamente profano. Asimismo, en el informe determinaban que si lo que primero que llama la atención al viandante-receptor es la fachada, y ésta debe remitir a su interior, la Universidad no podía ser deudora de cualquier imagen sacra. Sus señas de identidad tendrían que estar dentro de un nuevo orden de valores: el saber de las Ciencias y las Letras. También se percibe, en toda esta memoria, cierto desconocimiento patrimonial de las formas barrocas a proteger. Por aquel entonces, ya los ejemplos renacentistas españoles eran dignificados como patrimonio histórico, y el estilo gótico se comenzaba a restaurar en algunas regiones de España y Francia. Sin embargo, todavía el barroco andaluz y castellano eran denostados como pauta estilística desde los ambientes cercanos a la Academia, criticándose la obra de artífices como los Churriguera, Cano y Ribera.

10 V.V.A.A.: Op. Cit., pp. 111-114. 
El 30 de agosto de 1873 llegaba a Granada una carta de la Academia de Bellas Artes de San Fernando, donde se ponía de manifiesto la disconformidad con el estilo y decoración del proyecto, presentado al mismo tiempo la inadecuación de la sustitución de la portada. Ni siquiera sugirieron el levantamiento de su actual emplazamiento para configurar el nuevo eje de fachada con respecto a la plaza de la Universidad - denominada plaza de las Escuelas-. Por el contrario, sí daban la conformidad a la apertura de la calle Riaño siempre y cuando no implicara un derribo de parte de la Colegiata. Baglietto debía reestructurar así el diseño de todo el conjunto ${ }^{11}$. El Ayuntamiento, en palabras del alcalde, intentó que las obras comenzaran antes de llegar el dinero desde la Administración, sugiriendo otros métodos de financiación porque «hasta los periodicos de la Capital se han ocupado de la conveniencia que resultaría abriendose la calle proyectada y que ha de atravesar el Cuartel de la Compañía.

Esta importante obra no debe dejarse en el olvido, y mis exsitaciones se dirigian siempre a su realización, contando con la buena voluntad y cooperacion de V. S.

$A l$ intento serio de desear que $V$. S. removiendo los obstáculos que exsitan viera el medio de egecutar algo que invirtiera brazos trabajadores, dando principio á la demolicion de lo necesario, y tal vez con el producto de los materiales, se cubririan los gastos que ocasionen el Corte que debe darse al referido edificio»' ${ }^{12}$.

En 1873, la partida económica destinada por la Administración para la realización de las reformas no había llegado a Granada, y existían numerosas objeciones sobre la idoneidad de realizar ya la calle de Riaño. Baglietto había sido el primer responsable y artífice de las reformas de ampliación de la Universidad, pero cayó gravemente enfermo, muriendo en 1876. En ese sentido, tras el fallecimiento de Baglietto, el Rector nombra, con carácter de urgencia extrema a Juan Pugnaire como arquitecto encargado de la continuación de las obras. Éste desempeñaba el cargo de profesor de Matemáticas de la Universidad. El 23 de marzo de 1876 empezarían las obras de demolición de parte del Cuartel para realizar la comentada Calle de Riaño, aunque esto provocaría más de un susto al sacerdote responsable de la Colegiata de los Santos Justo y Pastor, cuya habitación daba a la parte del Cuartel que iba a ser demolida para abrir la calle de Riaño, quien mostró sus oportunas quejas.

El debate estético de la fachada jesuítica se reavivaba tras años de letargo por parte de la Inspección de Antigüedades de Granada y la Comisión de Monumentos Históricos y Artísticos de la Provincia de Granada. En carta fechada el 10 de junio de 1876, la citada Comisión de Monumentos se opuso a cualquier modificación de

11 Idem, p. 119.

12 Ibidem, p. 119. Carta del Alcalde al Rector de la Universidad de Granada, sin señalar referencia. 
la antigua portada de la Universidad, por lo que la Junta de Obras de la Universidad tuvo que revisar el proyecto, y atendiendo al Real Decreto de 16 de diciembre de 1873, relativo a monumentos histórico-artísticos ${ }^{13}$. Pugnaire estudió el proyecto del difunto Baglietto, remitiendo por escrito un mes más tarde, el 10 de julio de 1876, la imposibilidad de una adecuación de la fachada del proyecto con la portada existente. Juan Pugnaire escribía al respecto «Cumpliendo mi cometido de informar á esta Junta á cerca de la comunicación q[u]e le á dirigido la comision de Monumentos historicos de la Prov[inci]a relativa al deseo y conveniencia de que conserve la actual portada Salomonica q[u]e da entrada a este edificio Universitario debo informar lo que sigue.

Que estudiado con detenim[ien]to este asunto lo encuentro de difícil resolución, por no poderse armonizar los deseos de la Comision con el proyecto de la obra.

La adopcion de dicha portada p[ar]a la nueva fachada lleva consigo la modificacion del decorado general aprovado p[ar]a la misma, [...] La actual portada de la Universidad aunque del genero Salomonico con adornos del Churriguera, es no obstante una buena obra de arquitectura; ella es rica armoniosa, esvelta de buenas proporciones y de la mas perfecta egecucion, siendo toda ella de marmol pardo bruñido con incrustaciones de Macael, y con alegorias y escenas que recuerdan a su origen y su historia. Pasada la época de intolerancia en las artes, en que solo el gusto greco-romano imperaba con esclusion y aun desprecio de los demas, todos consideramos en lo que en si valen estos otros monumentos de arquitectura de otras épocas y de distinto género; y el sabe lo difícil que es hacer en este arte y la larga y penosa elaboracion p[or] la que pasa un proyecto desde que se concibe una idea hasta que se traduce en piedra el pensam[ien]to, no puede menos de condenar en principio la demolicion de esta clase de obras, sintiendo se convierta en fragmentos de lo que representa el trabajo de mucho tiempo, y las penosas operaciones de egecucion del materials ${ }^{14}$.

Es interesante esta fuente documental de Pugnaire, puesto que no sólo describe la inadecuación del proyecto anterior a la fachada de los jesuitas sino que su formación academicista se aprecia en el destacable no obstante que el arquitecto suscribe al calificar de buena una obra de corte salomónico y barroca; y con toda una declaración de buenas intenciones patrimoniales para revalorizar un arte olvidado por la Academia, recoge la idea de su importancia monumental y deber de conservación, entendido no como un ejemplo aislado sino como referencia cultural.

La idea del Rector era, a partir de entonces, la de trasladar solamente la vieja portada a la fachada visible desde la Plaza de la Universidad, y estar así, al centro

13 Ibidem, p. 120.

14 Ibidem, pp. 120-121. 


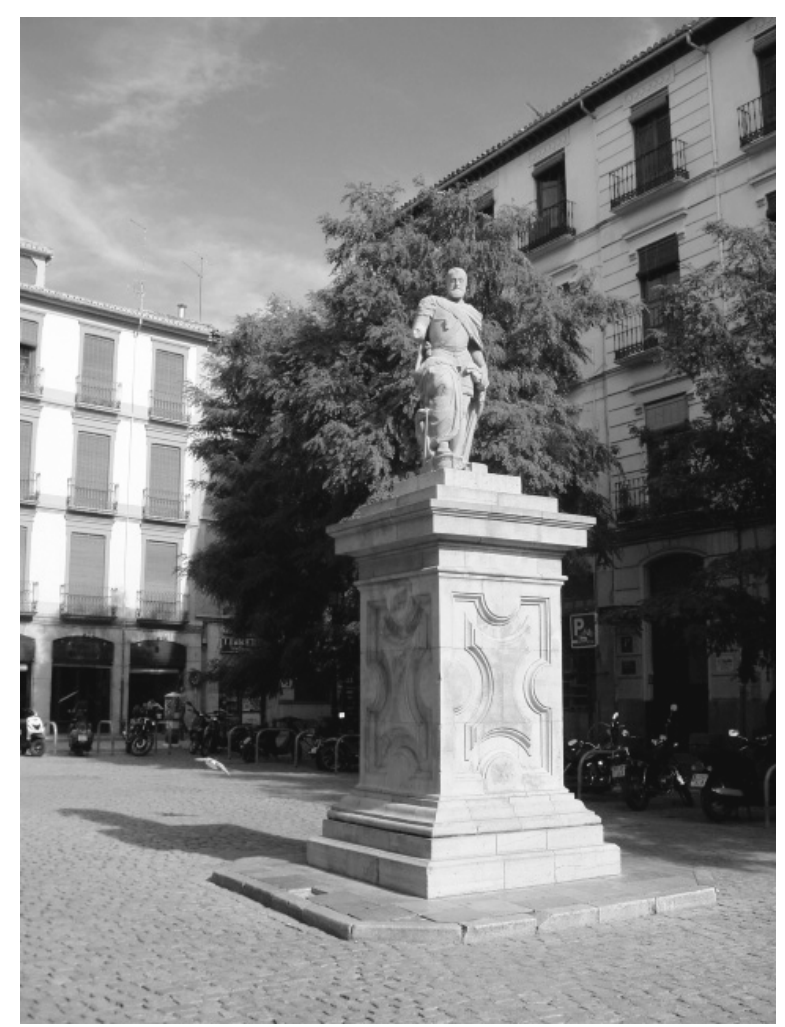

Fig. 4. Antigua Plaza de las Escuelas - actual Plaza de la Universidady escultura de Carlos V, Granada.

de ésta; pero la Inspección de Antigüedades de la Provincia de Granada se mostró contraria al traslado de la portada, pues no sólo ocasionaría gastos, sino daños irreparables que implicarían más que su reparación la total reconstrucción.

Otro de los argumentos que justificaban el mantenimiento de la misma está relacionado con el acceso al recinto de los estudiantes desde la plaza universitaria. Éstos, a la espera de las clases, no molestarían a los ciudadanos, pues la portada estaba ubicada en uno de los laterales de la plaza. Además, con la nueva calle de Riaño sería más fácil acceder y salir del recinto universitario, no entorpeciendo la actividad diaria de Granada.

La Comisión de Monumentos, aludía lo anteriormente comentado por la Inspección de Antigüedades, pero manifestaba también su disconformidad con la supuesta búsqueda de simetría con respecto a la plaza pues «[...] desaparecería la pintoresca perspectiva, esbeltez y elegancia que ofrece al espectador; sirviendo, 
como sirve, de fondo decorativo de una gran plaza, centro de muchas avenidas, $y$ de entrada secular al espacioso vestíbulo, patio y aulas de la Universidad y de su Paraninfo. Demas de esto, la portada se halla hoy en el centro precisamente de esta Escuela, ó sea en el de los grandes lienzos, el antiguo y el nuevo muro de fachada $[\ldots]$... 15 .

Interesante comentario de la Comisión provincial que inauguraría un nuevo concepto en el patrimonio español, en consonancia con el urbanismo andaluz y su instrumentalización política a lo largo de la historia. Se trata del pintoresquismo, en la reivindicación incluso de la esquina de la fachada como lugar idóneo para su ubicación por cumplir el requisito de lo romántico, y no desaparecer así la pintoresca perspectiva, tal y como afirmaban en el documento anterior. En 1876, Granada ya era el paradigma del romanticismo al Sur de Europa. Los viajeros cansados del Grand Tour hacia el Mediterráneo italiano, buscaban otras experiencias exóticas en el mundo hispanomusulmán, apreciando que se funden sincréticamente con las estructuras barrocas y mudéjares de la provincia. Desde la Comisión Provincial de Monumentos se intenta fomentar la visión de esta Granada, romántica y costumbrista, apreciable en las obras pictóricas de D. Roberts o G. Doré. Además define la Plaza de la Universidad como el entramado y centro de muchas avenidas — se trata de la plaza de la Encarnación, la calle de Riaño, San Jerónimo, de las Escuelas, y sus confluencias como la de Niños Luchando, que daba a la otra plaza aneja - fortaleciendo aún más esa imagen romántica preconcebida.

En 1877, justo tras un año como Arquitecto director de la Junta de Obras de la Universidad, Juan Pugnaire dejaría la reforma de la misma por estar enfermo no asistiendo a más de cuatro sesiones de la Junta de Obras desde enero hasta abril. Por su enfermedad, y debido al cansancio tras trabajar más de treinta años en la institución granadina como profesor docente de la cátedra de Matemáticas ${ }^{16}$, presenta la dimisión de su cargo.

En abril de 1877, designado por la Dirección de Obras Públicas de la capital española, dependiente del Ministerio de Fomento, llega Juan Monserrat y Vergés, arquitecto vecino de Madrid aunque de origen catalán como Director técnico ${ }^{17}$. Monserrat Vergés no residía en Granada por aquel entonces, encontrándose en

15 Ibidem, pp. 122-123.

16 Desde la sesión número 16 de la Junta de la Comisión de Reformas de la Universidad hasta la sesión número 20 de Juntas —es decir, desde el 26 de enero de 1877 hasta el 13 de abril de 1877- no existe la presencia del Arquitecto Director. Juan Pugnaire se encontraba mal de salud, y ya ni siquiera asistía a las reuniones, aunque figurara en el cargo. Es en abril de 1877 cuando se nombra a Juan Monserrat Vergés arquitecto director de las obras de reforma de la Universidad, pero uno de sus primeros trabajos se limitaría por orden de la Junta a proyectar lo mandado a la Real Academia de Bellas Artes de San Fernando de Madrid por Juan Pugnaire. A.H.U.G. Legajo 1100, Obras Públicas de la Universidad. s. c.

17 JEREZ MIR, C.: Guía de Arquitectura de Granada. Granada, Editorial Comares, 2003, p. 280. 


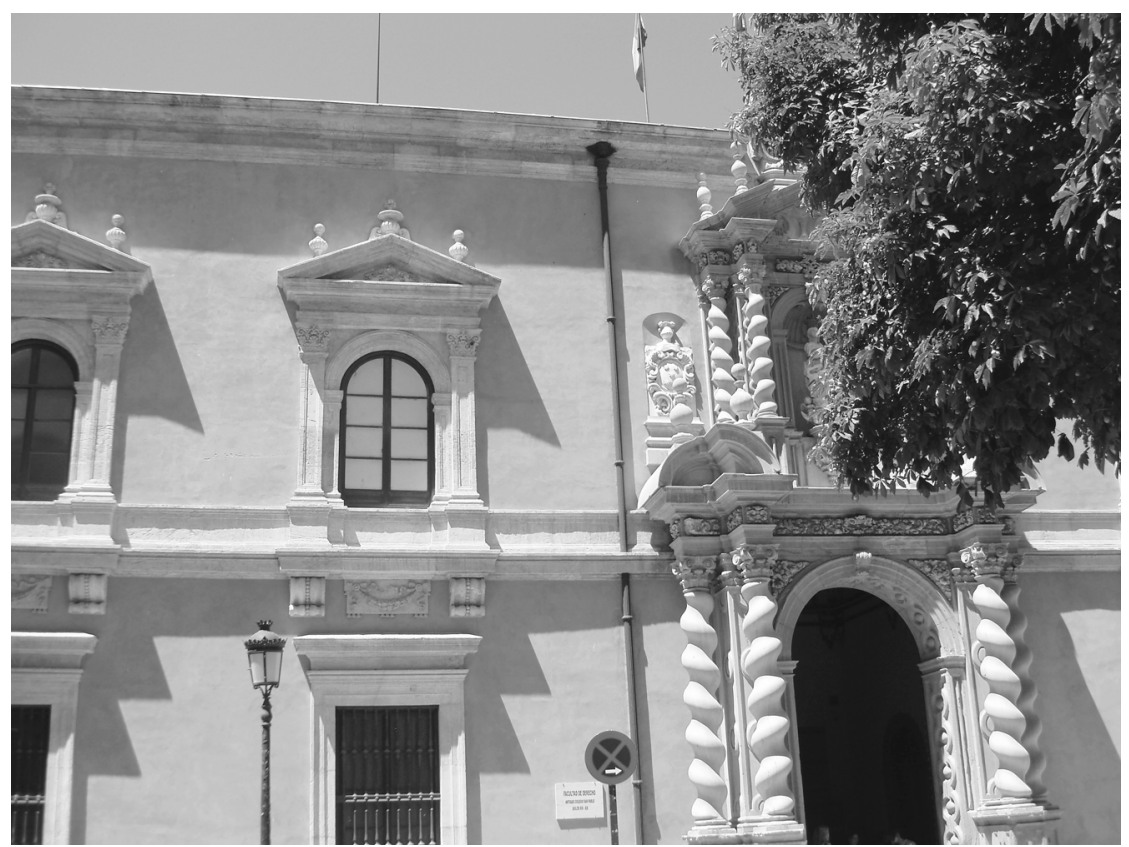

Fig. 5. Juan Monserrat y Vergés. Fachada de la Universidad Literaria (actual Facultad de Derecho) (1877-1789). Plaza de la Universidad, Granada.

Madrid trabajando y se le requiere para esta obra oficial, algo que cambiará radicalmente la vida de este arquitecto prometedor, que unos años antes de su venida a Andalucía había sido becado en la Academia Española de Roma, donde se conserva un retrato suyo ${ }^{18}$.

A su llegada a Granada, Juan Monserrat detentaría también los cargos institucionales de Arquitecto municipal de Granada, Arquitecto de la Diócesis de Granada y Arquitecto diocesano de Guadix-Baza ${ }^{19}$, además de arquitecto inspector de Hacienda para el Registro de Edificaciones y Solares.

${ }^{18}$ La serie de retratos de los becarios de la Academia de Bellas Artes de España en Roma comienza en 1881. Por esas fechas, este arquitecto trabajaba en España, concretamente en Granada. El retrato - muy probablemente - sería realizado a posteriori de su estancia como becario y enviado a Roma. RINCÓN GARCÍA, W.: «El autorretrato: ensayo de una teoría» en V.V.A.A.: El autorretrato en la pintura española: De Goya a Picasso, Catálogo de la Exposición homónima. Madrid, Fundación Cultural Mapfre Vida, 1991, p. 27.

19 Juan Monserrat Vergés es nombrado Arquitecto de la Diócesis de Guadix-Baza y de Granada en 1877, ocupando el cargo en Guadix-Baza hasta 1888, fecha en la que renuncia; un año más tarde hará lo mismo con el cargo de arquitecto diocesano del Arzobispado de Granada. RODRÍGUEZ DOMINGO, J. M.: «La Junta de Reparación de la Diócesis de Guadix-Baza (1845-1904)» Cuadernos de Arte, núm. 31 (2000), pp. 159-175. 
En 1879 realiza el proyecto de fachada que concluiría con el debate estético que se había suscitado en épocas anteriores. La laicidad de la fachada que sustentaba Montells y Nadal quedó atrás. Nadie creía conveniente ahora sustituir la portada inmaculista sino adecuar los vanos de su parte baja a un uso propio académico, con ventanales amplios que no recordaran la esencia claustral del colegio.

El valor neoclásico de los vanos, aunque barroquizados con guirnaldas, vendrían directamente en consonancia al diálogo que Monserrat Vergés impuso en sus composiciones tripartitas de los huecos con la portada barroca.

Su importante adscripción masónica, podría estar detrás de algunas pautas de ejecución de la fachada, además de la admiración por los maestros canteros del barroco, últimos gremios de cantería de la Granada del Antiguo Régimen, y que, especialmente, en la Masonería filosófica del siglo XIX causaba gran respeto. No debemos de dejar de resaltar que sus cargos en la Masonería granadina fueron muy relevantes y están intrínsecamente relacionados con determinadas proyecciones.

\section{GIMÉNEZ-ARÉVALO Y MONSERRAT VERGÉS: ANÁLISIS DE UNA INTROMISIÓN PROFESIONAL EN LA CATEDRAL}

En este ambiente provinciano, emergente pero decadentista a su vez, era en el que trabajaban numerosos profesionales arquitectos al servicio del municipio y de las instituciones públicas. Algunos de ellos tendrán grandes responsabilidades en el cuidado de la Alhambra y sentarán las bases teóricas y prácticas de las excavaciones y restauraciones hispanomusulmanas. Nombres relevantes como los Contreras, Modesto Cendoya, Juan Pugnaire, Santiago Baglietto, serían los encargados de remodelar la ciudad, pero al mismo tiempo, y como signo propio de toda época de esplendor, tendrán que remozar las fachadas de las casas de principios del siglo XIX y de aquellas antiguas mansiones del siglo XVIII. Granada, con lentitud crea otra imagen nueva, una imagen que puede tildarse de romántico-clasicista en muchas ocasiones, con fachadas de corte ecléctico, incluso seudomodernistas, o de cierto resabio historicista, de acorde a los nuevos parámetros estéticos de las ciudades. Ejemplos de estas soluciones son fachadas como la del desaparecido Convento del Ángel Custodio, proyectado bajo pautas neorrománicas según dibujo de Francisco Prieto Moreno y Velasco en $1908^{20}$ o las reformas efectuadas por Juan Monserrat Vergés en la Facultad de Derecho, con el ecléctico torreón-observatorio y el enverjado de su Jardín Botánico.

20 Aunque ya se había efectuado con anterioridad una readaptación de fachada — no historicistahacia la calle Barrecheguren por Juan Monserrat Vergés en 1899. BARRIOS ROZÚA, J. M.: La Granada desaparecida. Granada, Editorial Comares, 1999, pp. 256-257. 


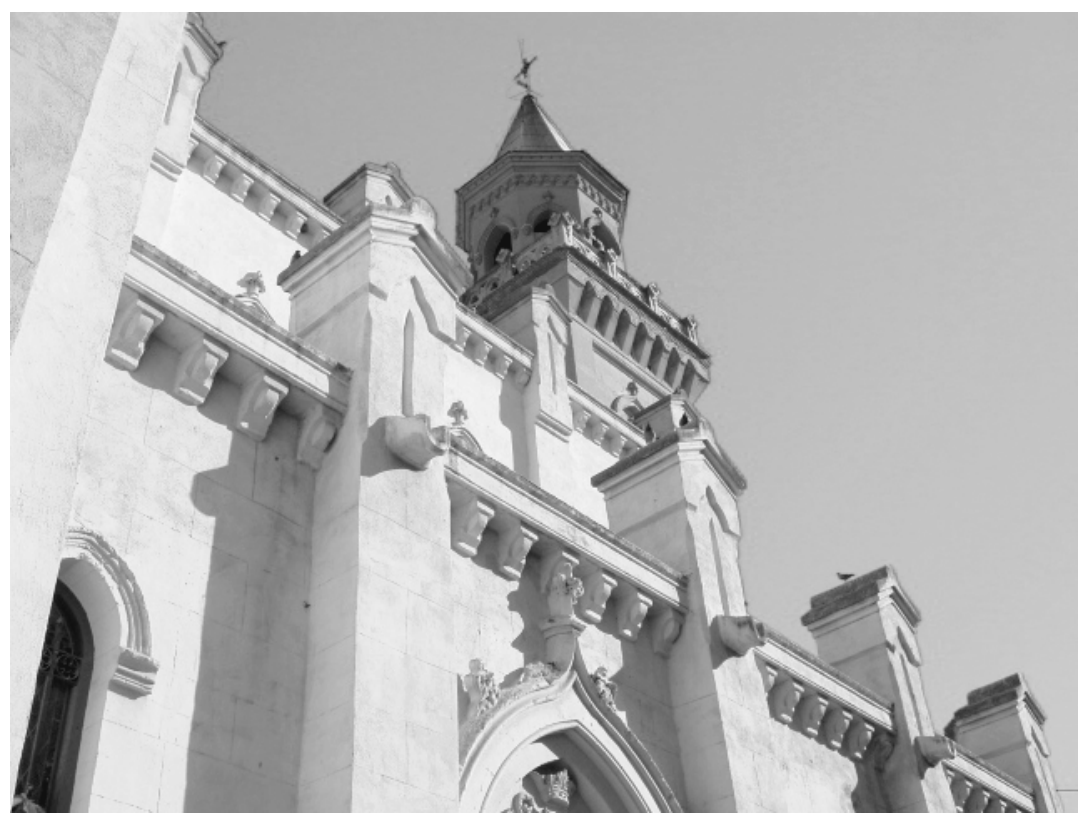

Fig. 6. Juan Monserrat y Vergés. Aspecto parcial del lateral de la Iglesia Parroquial de Nuestra Señora de la Encarnación (1900). Gabia la Grande, Granada.

La ciudad crecía y muchos eran los técnicos necesarios para su correcto control. Sin embargo, los maestros de obra no podían ejercer como facultativos en determinadas ocasiones, sobre todo en lo concerniente a construcciones de nueva planta o remodelaciones de conjuntos arquitectónicos de especial relevancia. En cuanto al patrimonio artístico eclesiástico, desde 1861 existían comisiones de valoración de las obras entre el Estado y la Iglesia, debiendo siempre estar al frente un Arquitecto-director de las reformas.

Juan Monserrat y Vergés, ocupando en Granada el cargo de Director de las reforma universitaria, desde abril de 1877, recibiría una notificación el 15 de diciembre que supondrá otro giro en su actividad profesional y que lo vinculará de por vida a esta ciudad. Es nombrado arquitecto del Arzobispado de Granada y, al mismo tiempo, de la Diócesis granadina de Guadix-Baza. Este nombramiento está directamente relacionado con una de las polémicas más interesantes y desconocidas de la Iglesia granadina, sin precedentes en la historia de la arquitectura española.

La trifurca, como si se tratara de un sainete literario, sucedió en las reformas de la Catedral de Granada. Los arquitectos municipales que configuraban la Comisión 
Provincial de Monumentos Históricos y Artísticos denunciaron rotundamente el claro intrusismo profesional por parte de un maestro de obras en las reformas de la Catedral de Granada, el industrial Francisco Giménez Arévalo.

Debido a esta flagrante actuación del Cabildo Catedral, que violaba los acuerdos obtenidos con Iglesia según Real Decreto de 1870, por el cual no podían ejercer ningún tipo de reforma en recinto sacro los maestros de obra sin la supervisión de un arquitecto director de la misma, la Comisión Provincial de Monumentos de la

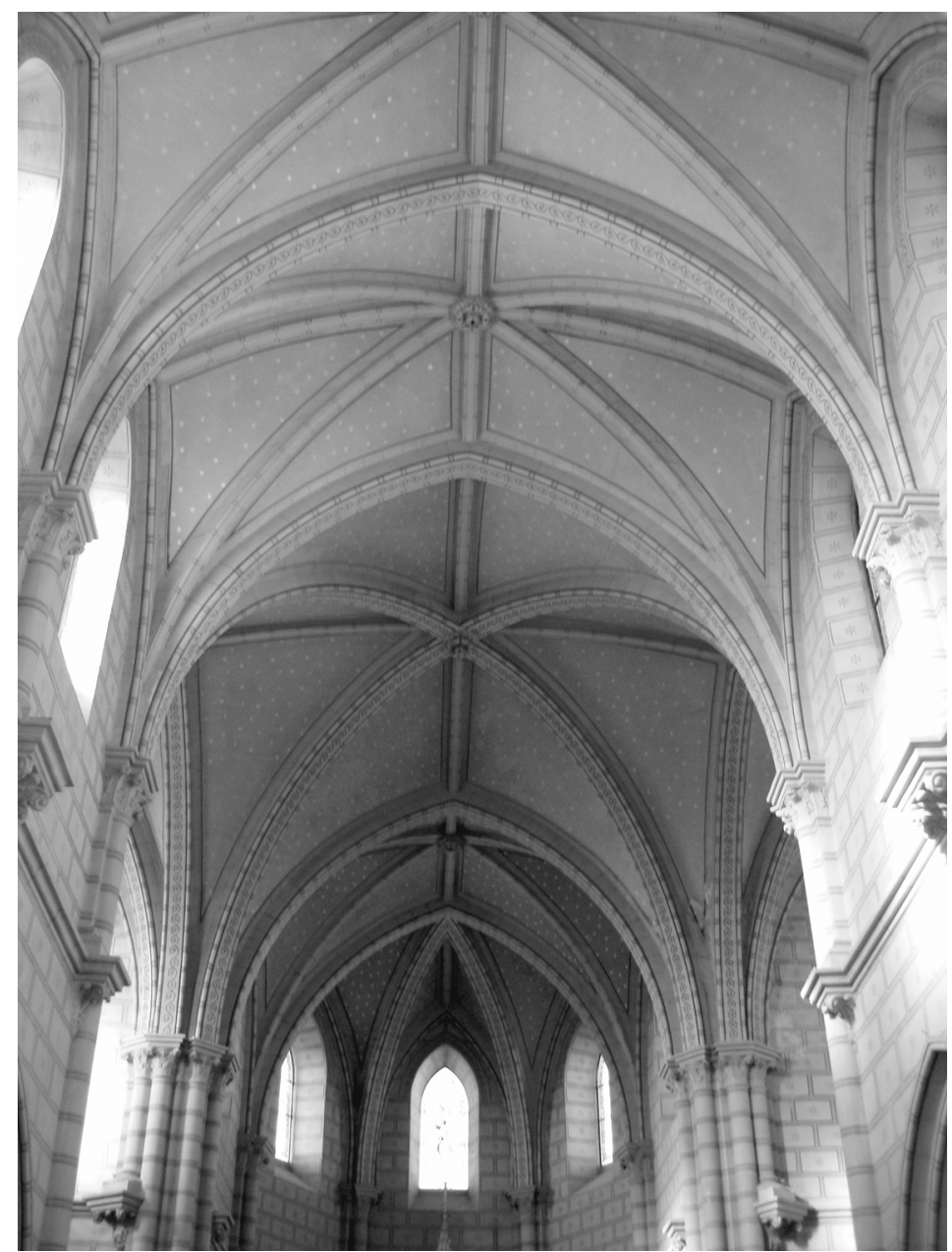

Fig. 7. Juan Monserrat y Vergés. Detalle de la bóveda estrellada. Iglesia Parroquial de Nuestra Señora de la Encarnación (1900). Gabia la Grande, Granada. 
ciudad protestaría formalmente ante la Real Academia de Bellas Artes de San Fernando y el Ministerio de Gracia y Justicia.

El día 2 de noviembre de 1877 la Comisión Provincial de Monumentos ponía en conocimiento de la Academia de San Fernando, a través de una importante carta-manifiesto, también dirigida en misma fecha al Gobernador de Granada, en la que manifestaban su malestar con el Arzobispado por realizar unas obras de reforma con ciertas irregularidades al tener como director de las mismas a un maestro de obra de la ciudad, Francisco Giménez-Arévalo.

En el comunicado se pedía rotundamente que se hiciera saber a la Catedral Metropolitana granadina que estaba incurriendo en un grave error e ilegalidad, según disposición de un Real Decreto de 1870, por la que los maestros de obras no podían ejecutar ningún tipo de obras o reformas, sino tan sólo los arquitectos titulados. Asimismo, el documento subrayaba lo absurdo de las obras planteadas, unas reformas de la solería de la Capilla Mayor, para dar así una mayor holgura en las celebraciones religiosas, principalmente en las misas y ceremonias de pontifical, cuestión que interfería en la línea de la traza y del espacio de tan singular construcción. La Comisión enfatizaba el valor patrimonial y singular de la sincrética catedral y lo inadecuado del proyecto. La carta concluye de esta forma siguiente, donde aparecen los firmantes de la Comisión reunida con urgencia, siendo ya Monserrat Vergés uno de sus miembros ${ }^{21}$ :

«Por tanto, y en cumplimiento del deber del cual no podemos prescindir, los que suscriben han denunciado el abuso ante la Academia de San Fernando al mismo tiempo que recurren á Us. En demanda de justicia = Suplicándole: que en observancia del decreto y Real Orden citados y por respeto á las Artes, se digne suspender la obra de la Catedral, denunciando el hecho ante el Gobierno de S. M., para que se tramite el expediente respectivo con arreglo á sus prescripciones legales. Dios gue. Á Us. Ms. as. Granada 2 de noviembre de 1877.= Juan Pugnaire, Fabio Gago= Juan Monserrat= Cecilio Díaz de Losada ${ }^{22}$.

El arquitecto municipal Cecilio Díaz de Lozada ${ }^{23}$, el mismo 2 de noviembre de 1877 escribe, en correspondencia no oficial, una carta personal a su maestro y

21 Por este dato, tan sólo y de momento, sabemos que Juan Monserrat y Vergés había participado en la Comisión Provincial de Monumentos Histórico-artísticos de Granada ante la Real Academia de Bellas Artes de San Fernando. En algunas ocasiones eran vocales natos de esta comisión los arquitectos municipales, por lo que y no encontrándonos con datos que justifiquen un nombramiento de Monserrat como Académico, su participación sería por ser uno de los varios arquitectos municipales de Granada.

22 Archivo Real Academia de Bellas Artes de San Fernando (ARABASF).Comisión Provincial de Monumentos, Granada. Carta de la Comisión Provincial de Monumentos a la Real Academia de Bellas Artes de San Fernando a 2 de noviembre de 1877, s. c.

${ }^{23}$ En la misma carta señala que es arquitecto municipal desde el 1 de agosto de 1870, y que desde 1872 se había caído en el ejercicio de su profesión. 
amigo, el Académico de San Fernando, Eugenio de la Cámara. Díaz de Lozada le da cuenta del escándalo catedralicio comentando en la misma cómo:

«[...] el señor Pougnaire [sic. aunque se trata del arquitecto Juan Pugnaire] ha dicho el disparate que se está cometiendo en la Catedral [... y le informa de todo]

El maestro, es un tal Fco. Jiménez Arevalo de los últimos que salieron de la escuela, y está ejerciendo aquí hace 4 ó 5 años. Es intrigante como el solo, y haciendo las obras por cuatro cuartos y con la recomendación de un ricachon de aquí, ha conseguido alzarse con la mayor parte del trabajo. Si tiene conocimiento de alguna obra [al parecer se presenta y no se va hasta que la consigue, ...] Con el trabajo que el ha prestado cualquiera estuviera rico, pero todo lo contrario: le cuadra perfectamente aquella de que el burro que más trabaja lleva el aparejo más roto [...]»24.

Díaz de Lozada continua la carta relatando la obra catedralicia y la ilegalidad de la misma, pues incumplía la normativa:

«[...] el Cabildo intenta hacer la mayor de la plataforma del Altar principal y hace una cuestación entre el mismo y algunos fieles. Al llegar á pedir caudal del banquero Agrela, este ofrece 100 duros a condicion de que dirija la obra el Jiménez que le está haciendo una casa; lo cual y al ser pariente de un canónigo según tengo entendido, fue lo suficiente para que recayera en aquel el nombramiento de director e hizo el proyecto» ${ }^{25}$.

Francisco Cubas, de la Sección de Arquitectura de la Academia de San Fernando, a 24 de noviembre de 1877, y en una carta a la Comisión Provincial de Monumentos de Granada, decía en nombre de la Academia que, efectivamente, la Diócesis Granadina y el Cabildo Catedral incurrían en el incumplimiento del reglamento de 12 de agosto de 1876, por lo que debían existir Comisiones con titulares profesionales -arquitectos-. Cuatro días más tarde, el 28 de noviembre de 1877, la Academia de San Fernando instaba al Ministro de la Gobernación para que nombrara de todos los arquitectos existentes en la ciudad de Granada, a un arquitecto titular, tal y como era preceptivo y existente en el resto de las Diócesis españolas, según la actualización de 1876 de la legislación previa de 1861.

Esta disposición de la Academia se haría efectiva, de tal manera que, en resolución del Ministerio de Gracia y Justicia, bajo Real Orden de 15 de diciembre de

${ }^{24}$ ARABASF. Comisión Provincial de Monumentos, Granada. Carta de Cecilio Díaz de Lozada a Eugenio de la Cámara a 2 de noviembre de 1877, s. c. Díaz de Lozada señala como uno de los último maestros de obras de la provincia a Jiménez Arévalo (sic.), que por esas fechas y en ocasiones se le ha vinculado con ser Ingeniero industrial. En este sentido, el empleo de ciertas alegorías por parte del maestro de obras en algunas viviendas suyas podría estar relacionado con su idea de dignificar su profesión aun habiendo una experiencia previa del empleo de estos moldes por parte de Monserrat Vergés. De todos modos, ambos profesionales llegan incluso a trabajar juntos proyectando el Hotel Colón.

25 ARABSF. Idem. 
1877, Juan Monserrat y Vergés sería nombrado Arquitecto diocesano no sólo del Arzobispado de Granada, sino además de la Diócesis de Guadix-Baza ${ }^{26}$.

Las quejas de los arquitectos que veían cómo las intromisiones profesionales se sucedían continuamente por parte de maestros de obra y albañiles, principalmente en los medios rurales de las Diócesis granadinas, quedaban reflejadas, dentro del ámbito oficial, en las memorias facultativas que llegaban a la Academia de Bellas Artes de San Fernando y al Ministerio de Gracia y Justicia. Tales hechos llevaron a algunos técnicos, como el arquitecto provincial de Almería, José Marín Baldo, a reivindicar rotundamente el papel del arquitecto frente a los maestros de obra y albañiles que en numerosas ocasiones eran los directores encargados de las reformas eclesiásticas en época del obispo Mariano Brezmes Arredondo ${ }^{27}$. De hecho, también Francisco Giménez-Arévalo, estaba encargado de algunas obras de reformas en la Diócesis de Guadix-Baza desde 1877. Tras la muerte en 1876 del arquitecto municipal de Granada, José Contreras, la Junta Diocesana le encargó el reconocimiento de la iglesia parroquial de Diezma ${ }^{28}$.

Juan Monserrat no mostró interés por el cargo de Arquitecto diocesano de Guadix-Baza. A petición del nuevo obispo, fray Vicente Pontes Castelar, titular de la cátedra desde 1876 hasta 1893, el arquitecto catalán debía aceptar dicho cargo, nombrado por el Ministerio de Gracia y Justicia en diciembre de 1877. La contestación positiva de Monserrat se dio, a través del Ministerio y desde Madrid, por encontrarse en la capital española en esas fechas, prometiendo llegar cuanto antes a Granada $^{29}$. Su ausencia se prolongó meses, hasta que, finalmente, se presentó ante la silla accitana el 20 de marzo de 1878, siendo ésta una de las pocas ocasiones en las que visitó la ciudad de Guadix ${ }^{30}$.

El obispo Pontes Castelar y la Junta Diocesana solicitaban una mayor atención por parte del arquitecto catalán. Monserrat, como uno de los primeros encargos diocesanos, debía informar sobre la manera de concluir la obra de la parroquial de Abla -Almería - que se había eternizado desde 1862, aunque estaba presupuestada desde 1858. Así, en 1880 después de una serie de dilaciones y contro-

${ }^{26}$ Archivo del Ministerio de Justicia (AMJ). Leg. 4005, exp. 20646 y exp. 20643. Citado en RODRÍGUEZ DOMINGO, J. M.: Op. Cit., pp. 173-175.

${ }_{27}$ Este caso conservado en el Archivo Histórico de la Diócesis de Guadix-Baza, presentado por el profesor Rodríguez Domingo, pone de manifiesto la situación que se venía produciendo en ambas diócesis granadinas desde mediados del siglo XIX. Cfr. RODRÍGUEZ DOMINGO, J. M.: Op. Cit., pp. 164165.

28 Idem, p. 168.

29 Sin embargo, a pesar de su ausencia en la provincia granadina, ya desde los primeros meses de 1877, Monserrat Vergés estaba al frente de la Dirección de las obras de reforma y ampliación de la Universidad Literaria de Granada.

30 RODRÍGUEZ DOMINGO, J. M.: Op. Cit., p. 173. 


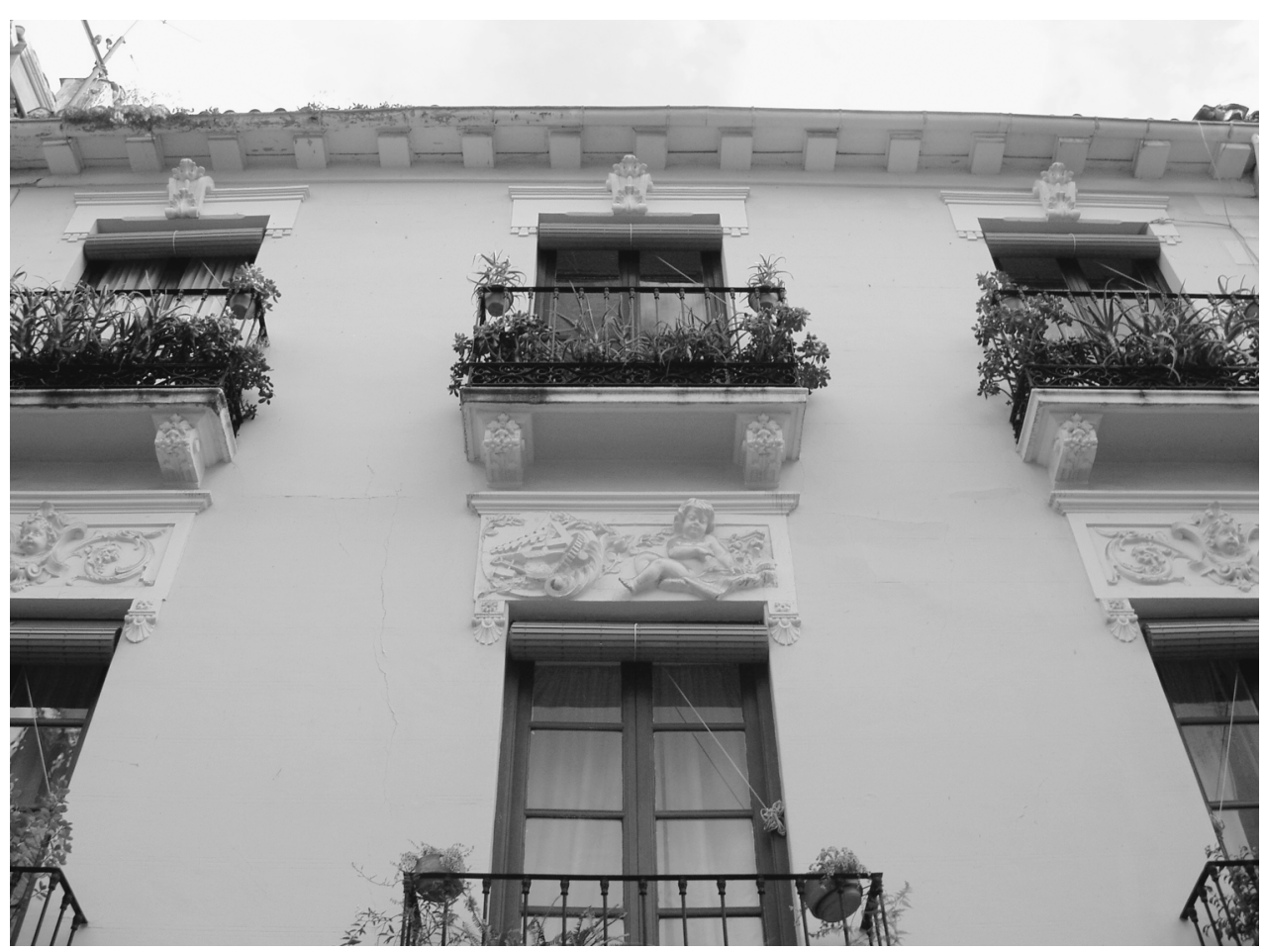

Fig. 8. Juan Monserrat y Vergés. Alegoría masónica y Casa de Juan Lisbona (1901). Calle Buen Suceso, Granada.

versias económico-administrativas con la Diócesis de Guadix-Baza, se acudió, paradójicamente, tras una dimisión temporal al facultativo Giménez-Arévalo, maestro de obras por el que había sido nombrado Monserrat y Vergés como sustituto en el Arzobispado de Granada.

Desconocemos la participación exacta de Juan Monserrat en la reforma catedralicia de esta época, aunque ciertas soluciones estéticas empleadas con posterioridad en la paradigmática iglesia parroquial de Nuestra Señora de la Encarnación en Gabia La Grande - Granada - nos remite a un conocimiento pleno y directo del templo-catedral. Al mismo tiempo, sería designado arquitecto municipal de Granada y, más tarde, arquitecto inspector de Hacienda para el Registro de Edificaciones y Solares. Pero Monserrat no sólo ocupó estos nombramientos públicos, sino que compaginó su actividad artística con la filantrópica dentro de las logias granadinas, siendo en 1890 presidente del Capítulo Provincial. Aparte de los cargos públicos e institucionales en la Masonería andaluza, también sería miembro fundador del Centro Artístico, Literario y Científico de Granada, así como contable 


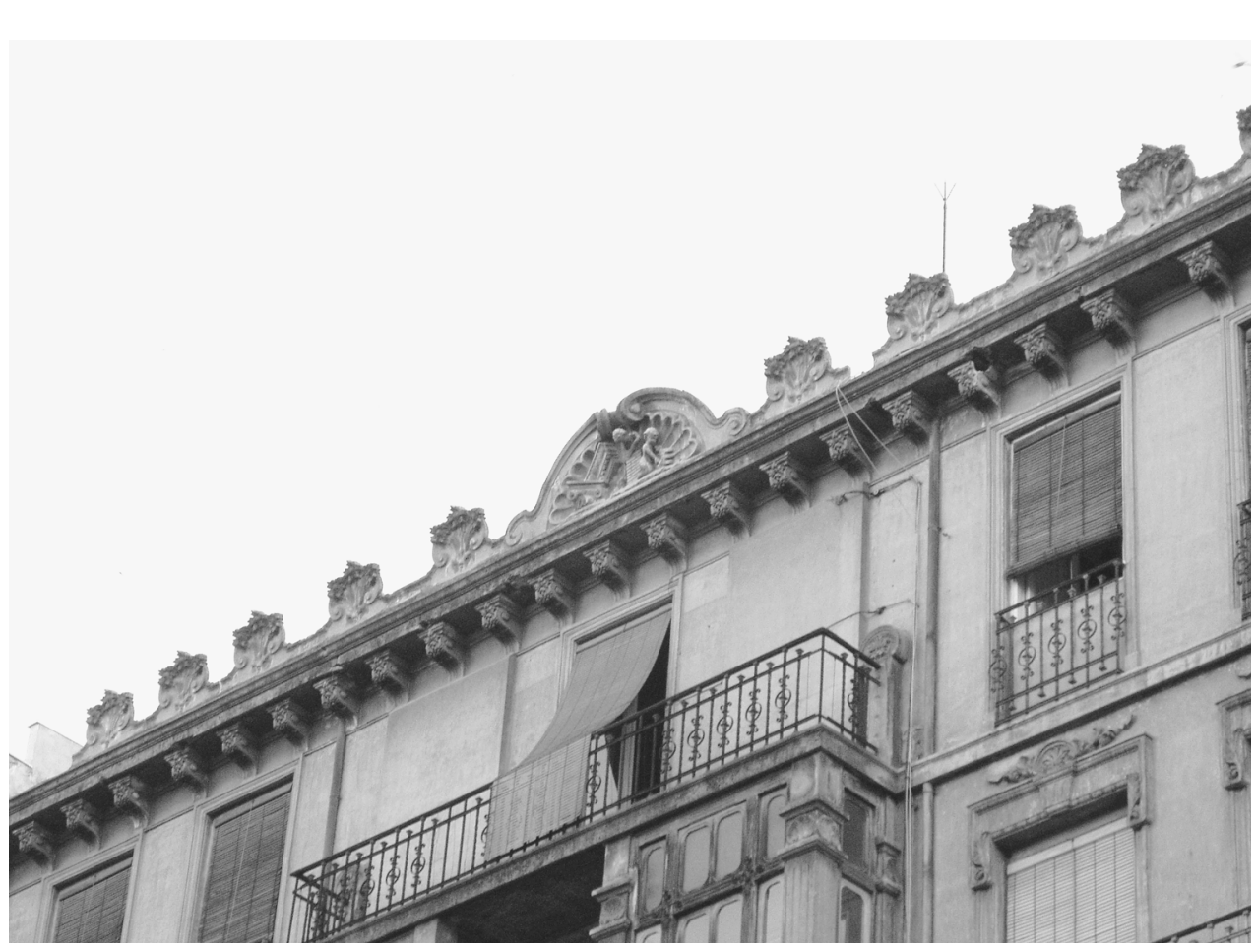

Fig. 9. Detalle alegórico masónico con niños constructores. Remate externo de un edificio de la Gran Vía de Colòn, Granada.

de la Sociedad obrera La Obra en enero de 1900, de la que fue elegido presidente honorario tal y como consta en el Semanario $X$ del día 21 de abril del mismo año.

Sus ocupaciones como arquitecto municipal y diocesano de Granada a finales del siglo XIx le hicieron dimitir de su cargo de Arquitecto de la Diócesis de GuadixBaza en 1888. A instancias del propio Monserrat, su cargo lo delegaba en José Ladislao Abásolo, arquitecto que trabajaba en Granada y era hermano de la Logia Beni-Garnata núm. 178 a la que Juan Monserrat Vergés pertenecía desde 1883. En 1889, renuncia también como arquitecto del Arzobispado, siendo sustituido de la misma forma por Ladislao Abásolo.

Innovador tanto en tipologías como en estilos, el talento creativo de Monserrat y Vergés pudo verse constreñido a la actuación en un ámbito provincial reducido, producto indiscutible de los dos nombramientos oficiales estudiados. Esto, por el contrario, le supuso no sólo fama en su época sino una extensa producción arquitectónica en la capital granadina. En este sentido, formaría parte de la generación 
de arquitectos municipales y provinciales, de las zonas periféricas españolas, como Trinidad Cuartara en Almería, Mariano Estanga en Tenerife. A todos ellos les tocó además de sanear la ciudad, planificar nuevas estructuras y tipologías constructivas como las viviendas de la clase obrera, hospitales, hoteles, mercados, fábricas, colegios o estaciones de trenes y ferrocarriles.

Juan Monserrat y Vergés destacó como profesional por su versatilidad estilística y tipológica. El neogótico de ciertas influencias británicas, apreciable en sus iglesias, o el gusto ecléctico de corte francés de la Banca Rodríguez Acosta o el Hotel Colón, serán dos de sus fórmulas estéticas más frecuentes, caso inusual en el ámbito granadino puesto que ninguna de sus producciones responden a lenguajes neoárabes. Adelanta y preconiza el modernismo con ciertos gestos en la ViIla Pineda, conjugando el estilo inglés con los novedosos cerramientos férreos.

Es el introductor de las tipologías de ventanas británicas oriel y bay window, desarrollada posteriormente por otros arquitectos en Granada como Fernando

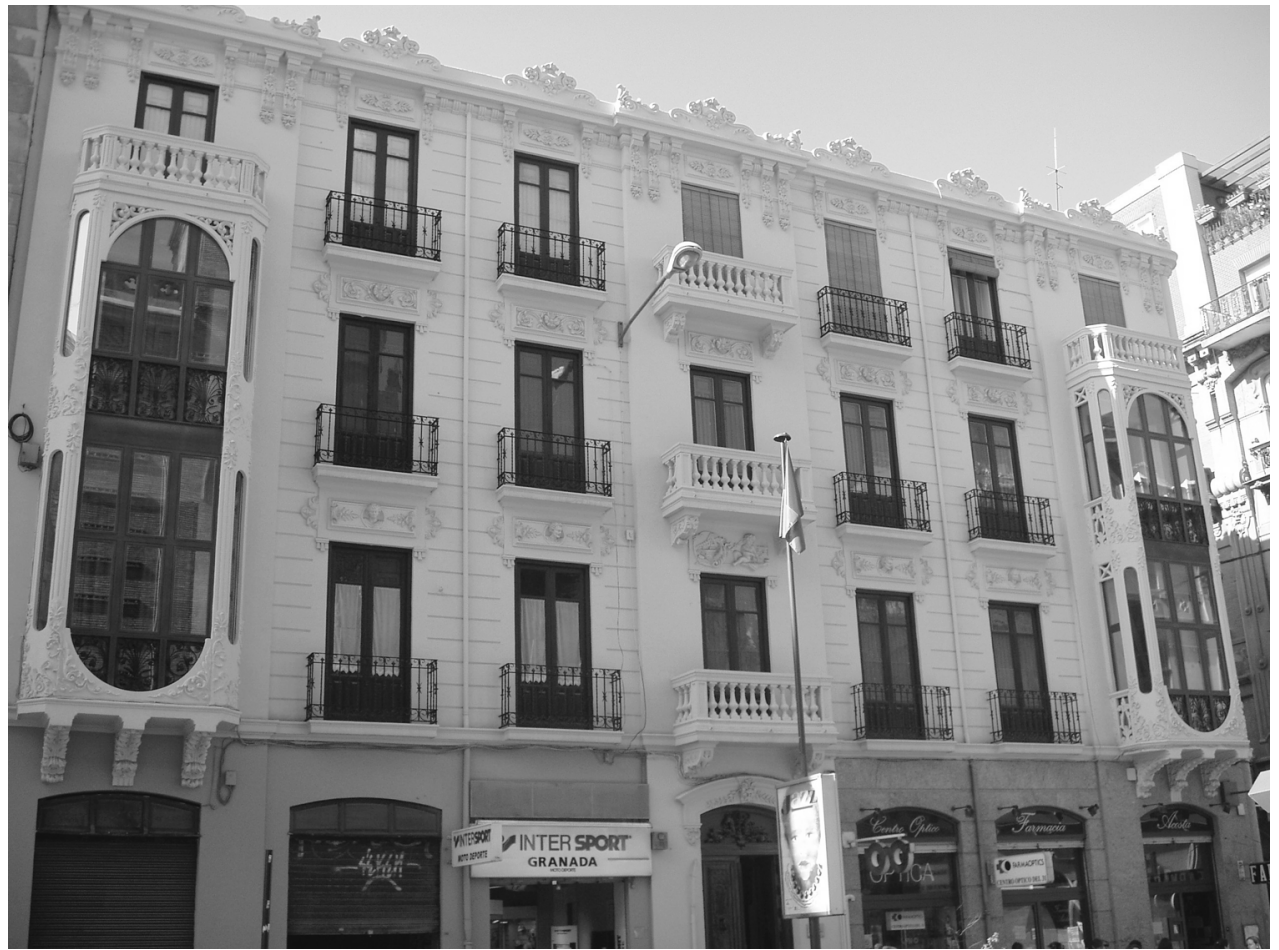

Fig. 10. Francisco Giménez-Arévalo. Residencia familiar y comercios (1906). Gran Vía de Colón núm. 27, Granada. 
Wilhelmi. No teme a los nuevos materiales como el hierro forjado a la hora de generar espacios públicos como los mercados municipales, y sobre todo conjuga con acierto moldes de cemento que reitera de manera utópica generando eclecticismos de notoria singularidad.

Realizó numerosas obras desde finales del siglo XIX, pero su producción más extensa se centra desde 1889 hasta 1910. Las más importantes son la reforma y fachada de la Antigua Universidad Literaria de Granada (1877-1886), el proyecto para la antigua Facultad de Medicina (1882) ${ }^{31}$, la proyección urbanística de la Plaza de la Trinidad, la iglesia parroquial de Gabia La Grande (1887-1900) ${ }^{32}$, la iglesia de Nuestra Señora de Monserrat, la Banca Rodríguez Acosta (1902) ${ }^{33}$, el Hotel Colón (1905), la Fábrica de azúcar del Marqués de Dílar (1890), la Pescadería Municipal34, o Villa Pineda (1908), la capilla de San Juan de Dios en la Calle Elvira, etc.

Giménez Arévalo como se deja entrever en la documentación de la Real Academia de Bellas Artes, y que ya se ha señalado en la historia económica de la provincia, poseía el control no sólo económico sino constructivo de la provincia de Granada a finales del siglo xIX y principios del siglo Xx. No obstante, es uno de los principales promotores, junto con el Presidente de la Cámara de Comercio de Granada, Juan López-Rubio, de la sociedad encargada de las obras de la Gran Vía. En dos residencias familiares suyas de este boulevard (núms. 27 y 12) incorpora un altorrelieve en el vano central del segundo cuerpo, configurado por herramientas gremiales que, en ocasiones, se ha planteado este altorrelieve como una alegoría que representa la dignificación de la arquitectura dado el agravio hecho por parte de los arquitectos granadinos desde 1877. Por tanto, el maestro de obras e ingeniero industrial proyectaría estos dos singulares edificios para su familia en la Gran Vía de Colón. El primero -núm. 12-, de corte eclecticista, fue realizado en 1904. El segundo -núm. 27-, se ejecuta en 1906, con una línea intermedia entre "[...] Historicismo y Modernismo, sobre todo en la hojarasca en relieve de sus miradores, a la que hay que añadir en el mismo estilo indeciso sus barandillas metálicas " ${ }^{35}$. Ambos, sin embargo, incorporarían en fachada la misma cartela o alto-

31 En la actualidad se ubica la Facultad de Ciencias Políticas, conservándose en el Salón de Grados, una hornacina ecléctica que bien pudiera ser del anterior edificio, no demolido en su totalidad.

32 GUILLÉN MARCOS, E.: «La iglesia de Gabia La Grande y los historicismos medievalistas en la arquitectura religiosa granadina» en CIRICI NÁRVAEZ, J. R. y ANTIGÜEDAD DEL CASTILLO-OLIVARES, M. D. (coord. y ed.): Arquitectura y ciudad en España. De 1845 a 1898. Cádiz, Servicio de Publicaciones de la Universidad de Cádiz, 2000, pp. 57-63.

33 JEREZ MIR, C.: Op. Cit., p. 302.

${ }^{34}$ GÓMEZ-MORENO, M.: Guía de Granada. Edición facsímil (1892) Tomo I. Granada, Universidad de Granada, 1982, p. 248.

35 VILLANUEVA MUÑOZ, E.: «Ciudad y arquitectura modernista en la Andalucía Oriental» en HENARES CUÉLLAR, I. y GALLEGO ARANDA, S. (eds.): Arquitectura y modernismo. Del historicismo a la modernidad, pp. 221-243, p. 233. 


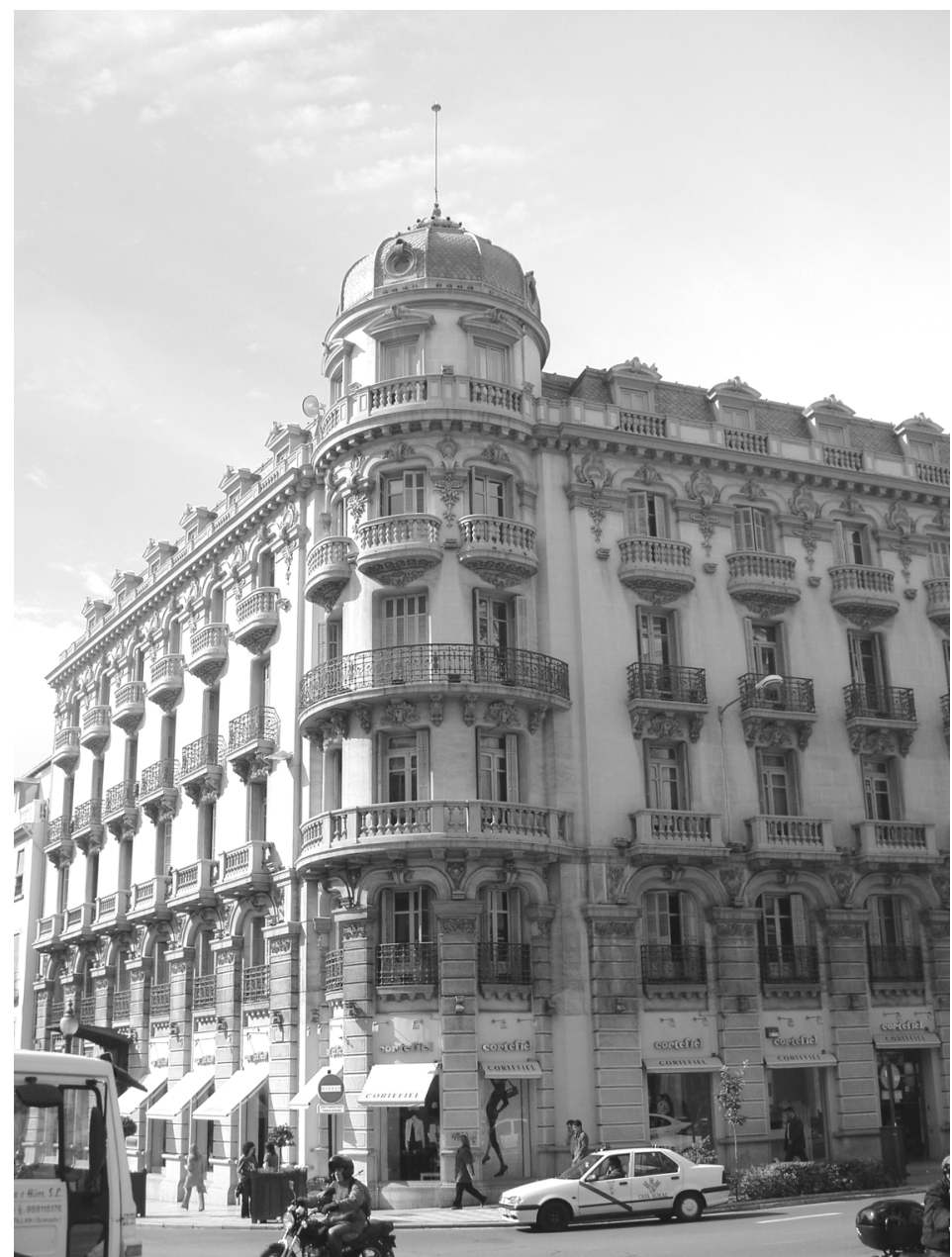

Fig. 11. Juan Monserrat y Vergés y Francisco Giménez-Arévalo. Hotel Colón (1902-1905). Gran Vía de Colón esquina Reyes Católicos, Granada.

rrelieve que, con anterioridad - tres años y cinco años respectivamente-, Juan Monserrat Vergés había planteado en la calle Buen Suceso para la casa de Juan Lisbona con un marcado carácter masónico ${ }^{36}$.

${ }^{36}$ El edificio más antiguo de los dos - actualmente núm. 12- de la Gran Vía, hace esquina con la calle Cetti Meriem, presentando una fachada eclecticista, como la mayoría de las construcciones de la calle, aunque con una cenefa en el techo del portal y una pintura, que «[...] de ser contemporánea del resto del edificio, sería la aproximación más antigua al Art Nouveau[...]» de Granada. VILLANUEVA 
La iconografía masónica que tiene en esta calle, deja tal vez de serlo en la posterior reutilización del relieve en la Gran Vía, dato que desconocemos pues las fuentes documentales, que han sido objeto de tesis doctorales, sólo han abordado el panorama de la Granada masónica hasta el siglo XIX, no figurando ninguno de los miembros de la familia de Giménez-Arévalo. No obstante, no debería ser interpretada como alegoría del arquitecto ni siquiera en las residencias del propio autor que lo incorporan en su domicilio de la Gran Vía y en el de su hermano, ya que los elementos que se representan no corresponden a la arquitectura propiamente dicha, puesto que constan en el relieve otros que son ajenos a la geometría -yunque, maza, pala - y que sí hablan de la maestría de obras, del artesanado y del componente gremial de la Masonería.

Paradojas de la historia de la arquitectura quisieron que el maestro de obras Giménez-Arévalo proyectara junto a Juan Monserrat y Vergés una edificación paradigmática en la Gran Vía granadina: el Hotel Colón (1905) ${ }^{37}$.

Con esta aproximación a dos debates importantes en el proceso arquitectónico de la ciudad de Granada podemos entender la complejidad de las relaciones institucionales y el resultado creativo de sus personajes. Todo ello debe interpretarse como fruto de decisiones y directrices ajenas a su creatividad, que marcarían a esta generación de profesionales, en busca de la modernidad absoluta.

\footnotetext{
MUÑOZ, E.: Op. Cit., p. 232. La pintura está firmada por R. Latorre, sin fecha aunque coetáneo al arquitecto. En el relieve escultórico se conserva el compás íntegro. Rafael Latorre es un pintor que trabaja por esas fechas en Granada, a caballo entre el modernismo y las tendencias románticas. Miembro del Centro Artístico, Científico y Literario de Granada, expuso en él en numerosas ocasiones a lo largo de su vida junto con Gómez Mir, Ruiz de Almodóvar, entre otros -Cfr. ALONSO GÓMEZ, J: La vida del Centro Artístico. Segunda parte (de 1908 a 1923). Granada, sin fecha-.

${ }_{37} \mathrm{Tal}$ y como señala la placa conmemorativa de su restauración, ubicada en el zaguán de la entrada principal del edificio. No obstante, en las publicaciones realizadas al respecto suele figurar como obra total de Monserrat y Vergés. JEREZ MIR, C.: Op. Cit. p. 28.
} 